\title{
Changes in the resistance to corrosion of thermally passivated titanium aluminide during exposure to sodium chloride solution
}

\author{
Ehsan Saebnoori • Taghi Shahrabi • \\ Hamidreza Jafarian • Mohammad Ghaffari
}

Received: 31 January 2013/Accepted: 2 May 2013/Published online: 25 May 2013

(C) Springer Science+Business Media Dordrecht 2013

\begin{abstract}
In this study the surface of Ti-47Al-2Cr (at. \%) was modified by heating and exposure to nitrogen gas flow to form a predominantly oxide layer on the surface. Samples were then immersed in Ringer's solution and 3.5 wt. \% sodium chloride solution and electrochemical impedance spectroscopy tests were performed at regular intervals. The results showed that the layer is highly resistant to corrosion. The equivalent circuit proposed for the impedance curves includes a Warburg element, because diffusion is controlling charge transfer through the passive surface layer. The resistance of the layer was not significantly reduced even after $300 \mathrm{~h}$ exposure to solutions and scanning electron micrographs showed the surface was not damaged.
\end{abstract}

Keywords Gamma titanium aluminide $(\gamma$-TiAl $) \cdot$ Corrosion · Passivation · Sodium chloride $\cdot$ EIS · Electrochemical stability

\footnotetext{
E. Saebnoori · T. Shahrabi $(\bowtie)$

Department of Materials Science and Engineering, Tarbiat Modares University, P.O. Box: 14115-143, Tehran, Iran e-mail: tshahrabi34@modares.ac.ir

E. Saebnoori

e-mail: saebnoori@modares.ac.ir

H. Jafarian

School of Metallurgy and Materials Engineering, Iran University of Science and Technology

(IUST), Tehran, Iran

M. Ghaffari

Department of Electrical and Electronics Engineering, UNAM-Institute of Materials Science and Nanotechnology, Bilkent University, 06800 Ankara, Turkey
} 


\section{Introduction}

Titanium aluminide-based alloys, are interesting because of their outstanding performance at high temperatures and their ability to withstand challenging environmental conditions. A new generation of TiAl alloys is being considered for a wide range of civil and military applications. Among these applications are high and low-pressure compressor blades, stators, casing and combustor components, fuel injector components, external casing, pipes and rotors of car turbochargers, and exhaust valves [1-3]. This intermetallic alloy has recently been introduced as a biomaterial for implantation [4-6].

The corrosion resistance of single $(\gamma)$ and duplex $(\alpha 2+\gamma)$ titanium aluminides is the same as, or better than, that of titanium, and the alloys also have higher yield strength and rigidity and are of lower density than common titanium alloys. When heated to high temperatures titanium aluminide forms a bio-inert oxide layer which is resistant to both corrosion and wear [5, 7]. It has been reported that titanium oxide debris on titanium implants as a result of wear results in immunological response of the body and, eventually bone-metal detachment [8]. $\gamma$-TiAl implants preferentially form aluminium oxide [9], which is more wear and fretting resistant. As a result immunological responses are prevented.

Investigation has revealed that Ti-6Al-4 $\mathrm{V}$ might release vanadium, which is toxic and increases biological problems [10]. Use of $\gamma$-TiAl as a substitute for Ti-6Al-4 V can prevent vanadium problems and, therefore, its effects on the boneimplant interface are reduced. Preliminary investigation of $\gamma$-TiAl in-situ implantation in rats with cell attachments and osteoblast cell culture showed that the tissue response was suitable and the alloy is acceptable for use as an implant [6]. In another study, corrosion resistance of $\gamma$-TiAl in simulated body fluid was evaluated to assess the possibility of its being used as a biomaterial; the results showed corrosion resistance is similar to that of Ti-6Al-4V in the same solution [4]. In addition, thermal treatment of the alloy in air resulted in oxidation, resulting in good corrosion resistance in sea water [11].

Titanium alloys have a strong tendency to react with oxygen, which increases formation of an adherent oxide barrier layer; this is the reason for the high corrosion resistance of these materials. In biological applications, chemical composition and the stability of the oxide layer are important, because the biomaterial surface is directly exposed to biological tissues [12]. Thermal oxidation of titanium alloys is a well known means of improving corrosion resistance. Many investigations [4, 13] have been performed to optimize this thermal treatment. In an investigation by García-Alonso et al. [8], the effect of thermal oxidation of Ti-6Al-4 V on corrosion behavior and in-situ osteoblast cell-culture response was evaluated. In another study by Güleryüz and Çimenoglu [13], Ti-6Al-4 V was heated for $60 \mathrm{~h}$ at 600 and $650{ }^{\circ} \mathrm{C}$, and it was observed that corrosion resistance was improved by formation of an oxide layer consisting of anatase and rutile. Lu et al. [14] studied the process of oxidation of Ti-45Al-8Nb-0.2W-0.2B-0.02Y (at. \%) for $100 \mathrm{~h}$ at $900{ }^{\circ} \mathrm{C}$. They showed that $\mathrm{TiO}_{2}$ and $\mathrm{Al}_{2} \mathrm{O}_{3}$ were present in the metastable oxide layer even in the at early stages of oxidation, i.e. during first $5 \mathrm{~min}$. In another investigation, the surface of $\gamma$-TiAl was treated in an autoclave and by oxidation in air. It was 
observed that the surface oxidized at 500 and $800{ }^{\circ} \mathrm{C}$ had outstanding corrosion resistance in comparison with untreated $\mathrm{Ti}-48 \mathrm{Al}-2 \mathrm{Cr}-2 \mathrm{Nb}$, which is characterized by high polarization resistance, high noble corrosion potential, and lower corrosion current density and rate of corrosion [4].

As previously mentioned, heating alloys at rather high temperatures is a method for ceramic layer formation to improve corrosion resistance. For binary $\mathrm{Ti}-\mathrm{Al}$ alloys, the oxidation products are oxides of $\mathrm{Ti}$ and $\mathrm{Al}$, including rutile titania $\left(\mathrm{TiO}_{2}\right)$ and alpha alumina $\left(\mathrm{Al}_{2} \mathrm{O}_{3}\right)$, among others. In comparison with alumina, titania is more conductive and less protective. Nevertheless, similar activity for titanium and aluminium lead to the formation of both titania and alumina simultaneously [15, 16]. In most of the literature, the oxide layer is discussed from the perspective of oxidation resistance, but there is a lack of knowledge about protection of this layer against electrochemical corrosion at ambient temperature [17]. Even so, the ceramic layer can improve the characteristics of the alloy, including better protection at ambient temperature.

In our previous study [7], a $\mathrm{Ti}-47 \mathrm{Al}-2 \mathrm{Cr}$ (at. \%) alloy was heated at different temperatures, $750,850,950$, and $980{ }^{\circ} \mathrm{C}$, in the presence of a flow of nitrogen gas and the surface was thermally passivated. The results confirmed that the sample treated at $950{ }^{\circ} \mathrm{C}$ had the highest resistance. In this study, the electrochemical behavior of the sample with the best modification (i.e. that treated at $950{ }^{\circ} \mathrm{C}$ ), was examined after exposure to sodium chloride solutions for different times, to determine the stability of the oxide layer in the presence of chloride ion.

\section{Experimental}

Titanium aluminide was cast and remelted in a vacuum arc remelting (VAR) furnace with non-consumable tungsten electrode. Relatively pure raw materials were used (titanium rod of purity $99.7 \%$; aluminium ingot of purity $99.9 \%$; chromium granules of purity $99.97 \%$ ). To prepare the Ti-47Al-2Cr alloy, Ti, Al, and $\mathrm{Cr}$ with the weigh percentages 64.07, 33.21, and $2.72 \%$, respectively, were precisely weighed then degreased with acetone in an ultrasonic bath for $20 \mathrm{~min}$.

Melting and alloying was performed under an argon atmosphere at a pressure of 300 mbar in a copper water-cooled mold with vacant space of dimensions $10 \times 2 \times 1 \mathrm{~cm}^{3}$. To achieve homogenous composition and remove microscopic segregation, the alloy was remelted five times. The ingot was placed in a quartz vacuum tube ( 0.5 torr) and the homogenizing heat treatment was performed below the eutectic temperature of $1,125{ }^{\circ} \mathrm{C}$. The final microstructure consisted of $70 \%$ lamellar gamma phase and $30 \%$ blocks of gamma and alpha phases (not shown).

The samples of $\mathrm{Ti}-47 \mathrm{Al}-2 \mathrm{Cr}$ were cut into $30 \times 20 \times 5 \mathrm{~mm}^{3}$ sheets then abraded by use of silicon carbide paper (up to 1,200 grit) before surface treatment. The samples were then degreased with ethanol and rinsed with distilled water. To ensure a completely clean surface and removal of natural surface oxides, the samples were acid pickled in $30 \%$ sulfuric acid for $10 \mathrm{~min}$. In the next stage, the sample was heated at $950{ }^{\circ} \mathrm{C}$ in nitrogen gas flow for $1 \mathrm{~h}$. Additional details are presented in Ref. [7]. 
Cross-section compositional and elemental analysis was performed with a Cambridge S360 SEM equipped with an Inca Operator EDS detector. Surface analysis of the sample was also performed by scanning electron microscopy (SEM) (Philips XL30 SEM with EDS detector).

Electrochemical testing was performed in Ringer's solution $(8.402 \mathrm{~g} / \mathrm{l} \mathrm{NaCl}$, $0.302 \mathrm{~g} / 1 \mathrm{KCl}$ and $0.298 \mathrm{~g} / \mathrm{C} \mathrm{CaCl}_{2}$ ) and in $3.5 \% \mathrm{NaCl}$ solution. Electrochemical impedance spectroscopy (EIS) was performed with different exposure time.

EIS tests were performed by applying a $10-\mathrm{mV}$ perturbation at open circuit potential. The ac frequency ranges varied from $100 \mathrm{kHz}$ to $10 \mathrm{mHz}$. An EG\&G potentiostat with 1,025 frequency response detector was used for plotting EIS curves. Power Suite software was used for measurement of impedance and the Zview software was used to fit the proposed equivalent circuits. Electrochemical testing was performed to ASTM G5 standard in an EG\&G flat cell with saturated calomel reference electrode, platinum mesh counter electrode, and $\mathrm{Ti}-47 \mathrm{Al}-2 \mathrm{Cr}$ alloy working electrode. The solution temperature was not controlled and was left at ambient temperature.

\section{Results and discussion}

Figure 1 shows line scan analysis of the cross section of the sample thermally treated at $950{ }^{\circ} \mathrm{C}$ in an atmosphere of nitrogen gas flow. Although in this sample the titanium content is higher than that of aluminium, in the surface layer formed the opposite trend is observed and the aluminium was present in greater quantities than the titanium. Furthermore, the variation of nitrogen levels shows that nitrides exist throughout the layer, and that the quantity increases with depth. The titanium depth profile to a depth of $2 \mu \mathrm{m}$ from the outer surface includes a peak which indicates a titanium oxide-rich portion in the layer.

At a depth of $15-20 \mu \mathrm{m}$ in the oxide layer, the concentration of titanium compounds (oxides, nitrides, or metal) is greater than that of aluminium compounds; at shorter distances from the surface aluminium compounds predominate. Variation of elements with depth is shown in Fig. 1.

Analysis of the surface oxide layer is shown in Fig. 2. In the inner parts of the surface oxide layer, compaction is greater than that in outer part, because the outermost surface is of high porosity. Maps showing the distribution of elements (elemental analysis) in selected parts of the surface oxide layer and the layer beneath are shown in Fig. 3. Uniform distribution of the elements can be observed in both the oxide layer and the alloy.

Results from EDS analysis of a surface selected from the whole thickness of the surface oxide layer are presented in Table 1. Here, more than 5 atomic percent of nitrogen was detected. As can be seen, the atomic percentage of titanium is greater than that of aluminium and the substantial amount of oxygen implies that the layer is mostly oxide. This analysis varied at different points; sometimes the amount of nitrogen was lower or even negligible. It is also noticeable that the chromium content of the surface layer was negligible. Although the alloy contains 2 atomic percent of chromium, on average there was only $0.12 \%$ in the surface layer. 

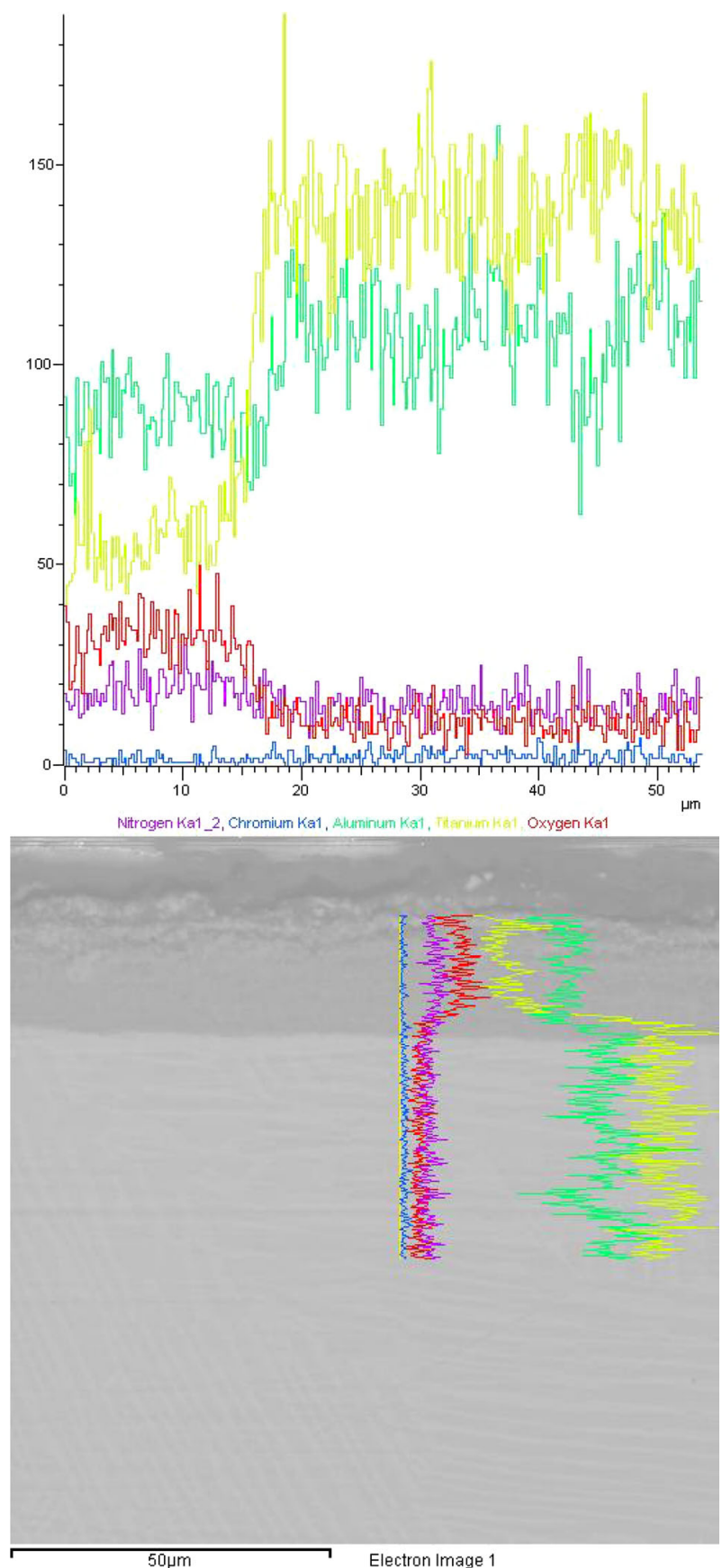

Fig. 1 Line scan analysis of the oxide layer formed on the surface of a sample of Ti-47Al-2Cr modified at $950{ }^{\circ} \mathrm{C}$ 

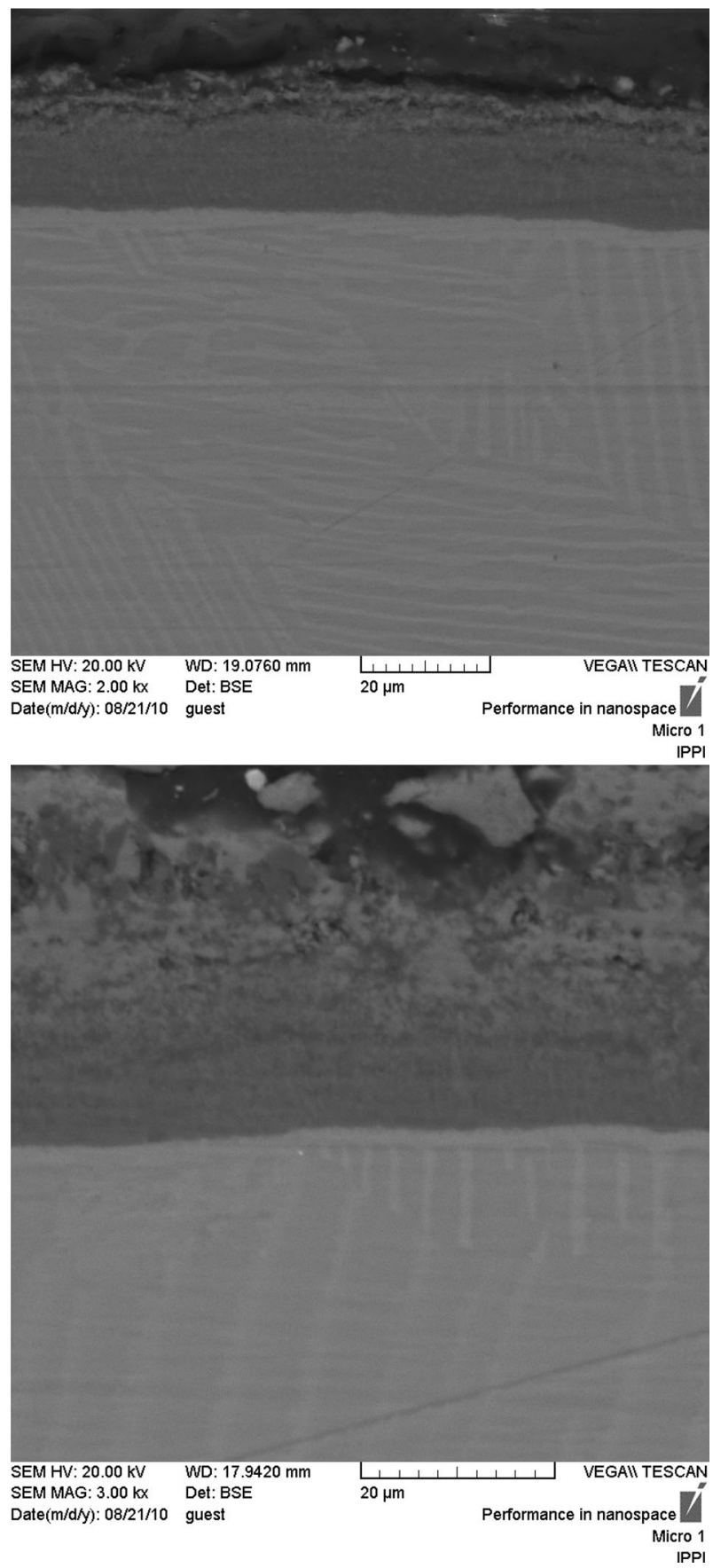

Fig. 2 Cross-sectional scanning-electron microscope image of surface oxide film formed by thermal treatment of $\mathrm{Ti}-47 \mathrm{Al}-2 \mathrm{Cr}$ at $950{ }^{\circ} \mathrm{C}$ 

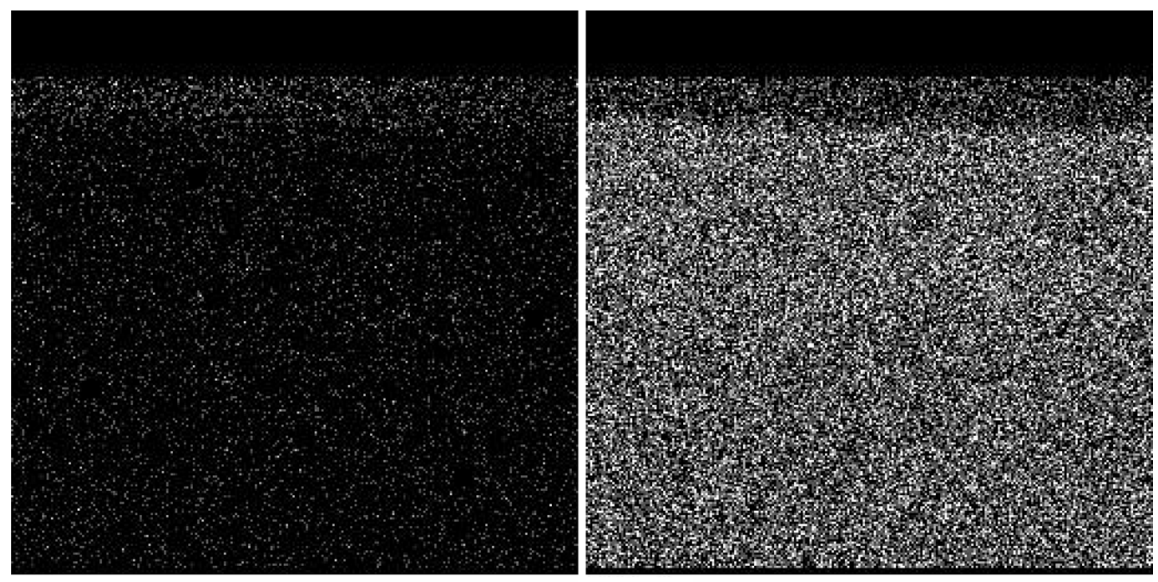

\section{$0 \mathrm{Ka} 1$}

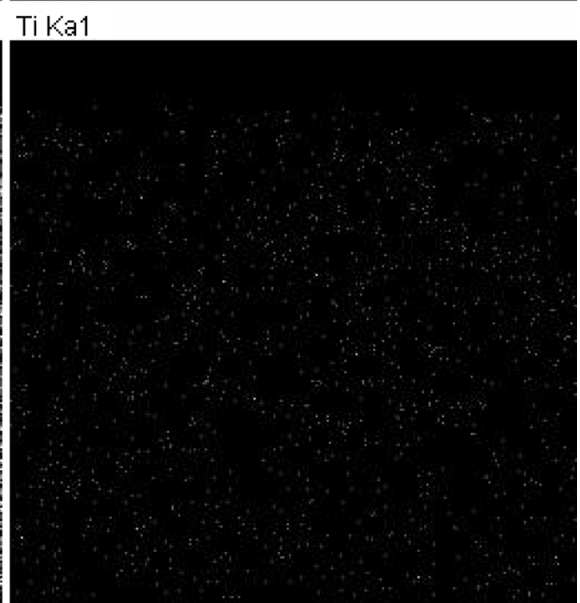

Al Ka1

\section{Crka1}

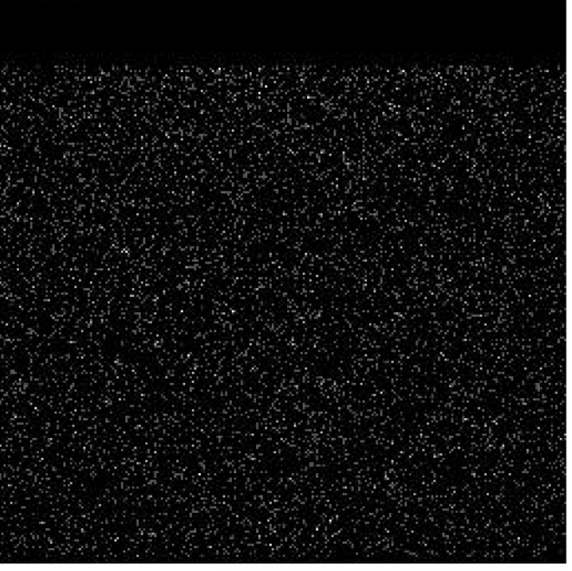

NKa1_2

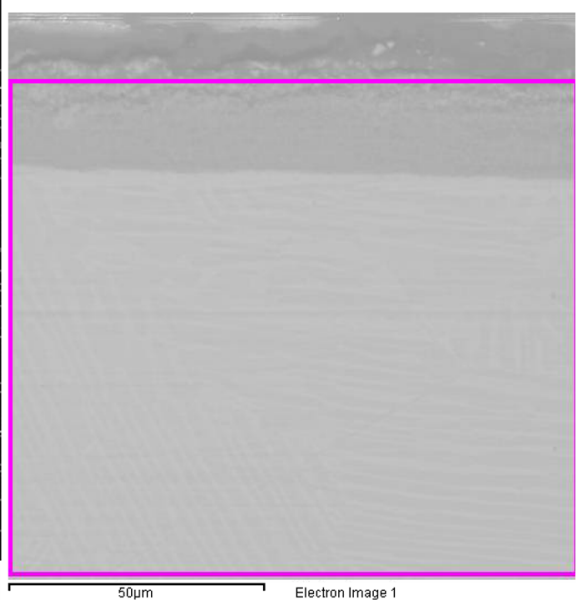

Fig. 3 EDS map analysis from of a cross section of the substrate and surface oxide film formed by thermal treatment of $\mathrm{Ti}-47 \mathrm{Al}-2 \mathrm{Cr}$ at $950{ }^{\circ} \mathrm{C}$ 
Table 1 Elemental analysis of the part of the oxide layer marked in Fig. 2

\begin{tabular}{lcc}
\hline Element & Weight $(\%)$ & Atom (\%) \\
\hline $\mathrm{N}$ & 2.73 & 5.85 \\
$\mathrm{O}$ & 16.05 & 30.16 \\
$\mathrm{Al}$ & 26.78 & 29.84 \\
$\mathrm{Ti}$ & 54.23 & 34.03 \\
$\mathrm{Cr}$ & 0.21 & 0.12 \\
Totals & 100.00 & 100.00 \\
\hline
\end{tabular}

It has been reported that in pure oxygen a continuous dense layer of $\mathrm{Al}_{2} \mathrm{O}_{3}$ is formed on $\mathrm{Ti}-\mathrm{Al}(47-49$ at. \%) and that at lower oxygen content the presence of titanium oxide in the surface oxide layer would be greater [18, 19]. It has also been mentioned that higher aluminium content is needed for the alloy to form a barrier of alumina. By thermodynamic calculation it has been shown that for titanium aluminide with $50 \%$ aluminium content or less, the titanium oxide is more stable than the aluminium oxide [18]. Moreover, increase in the nitrogen partial pressure in the gas flow enhances the amount of nitride phases.

On the basis of these observations, it can be predicted that surface modification of Ti-47Al-2Cr samples by thermal treatment in the presence of nitrogen gas flow is suitable for improving corrosion resistance.

To evaluate the stability of the formed layer over time, electrochemical impedance spectroscopy testing was performed on samples treated at $950{ }^{\circ} \mathrm{C}$ then placed in Ringer's solution or in $3.5 \% \mathrm{NaCl}$ solution at open circuit potential.

Figure 4 shows the impedance curves acquired after exposure for different times in Ringer's solution. It is apparent from the Nyquist and Bode modulus diagrams that there is high resistance in the system and the impedance at low frequencies is of the order of some 10 billion ohms. The Bode phase diagram shows that the curve is almost falling and starts from about 90 degrees at high frequencies and decreases steadily to low frequencies and finally slightly increases. Large angles at the start of the Bode phase diagram are indicative of high resistance of the surface layer. In addition, no peak in the Bode phase diagrams suggests one RC loop in the equivalent circuit. The almost linear plot at low frequencies, with slope of -1 , suggests the presence of a Warburg element in the equivalent circuit; this, in turn, suggests diffusion of a reactant or a reaction product on the surface of the electrode which occurs here for charge carrier diffusion through the barrier surface layer. In general, when the mechanism of an electrochemical process is under control of the diffusion effect, the impedance response is characterized by a unique element known as the Warburg element. For this response, the current differs by $45^{\circ}$ from the applied potential, so that at all frequencies the real and imaginary parts of impedance vector would be the same. The impedance behavior of a Warburg element (phase difference of $45^{\circ}$ ) is behavior between a resistor (phase difference $0^{\circ}$ ) and a capacitor (phase difference $90^{\circ}$ ). There is no simple element to describe the Warburg impedance so it is represented with a W [20].

The value of $\mathrm{Z}$ for a system controlled by diffusion changes by the second root of frequency. So, the Warburg impedance can be written as the complex number: 

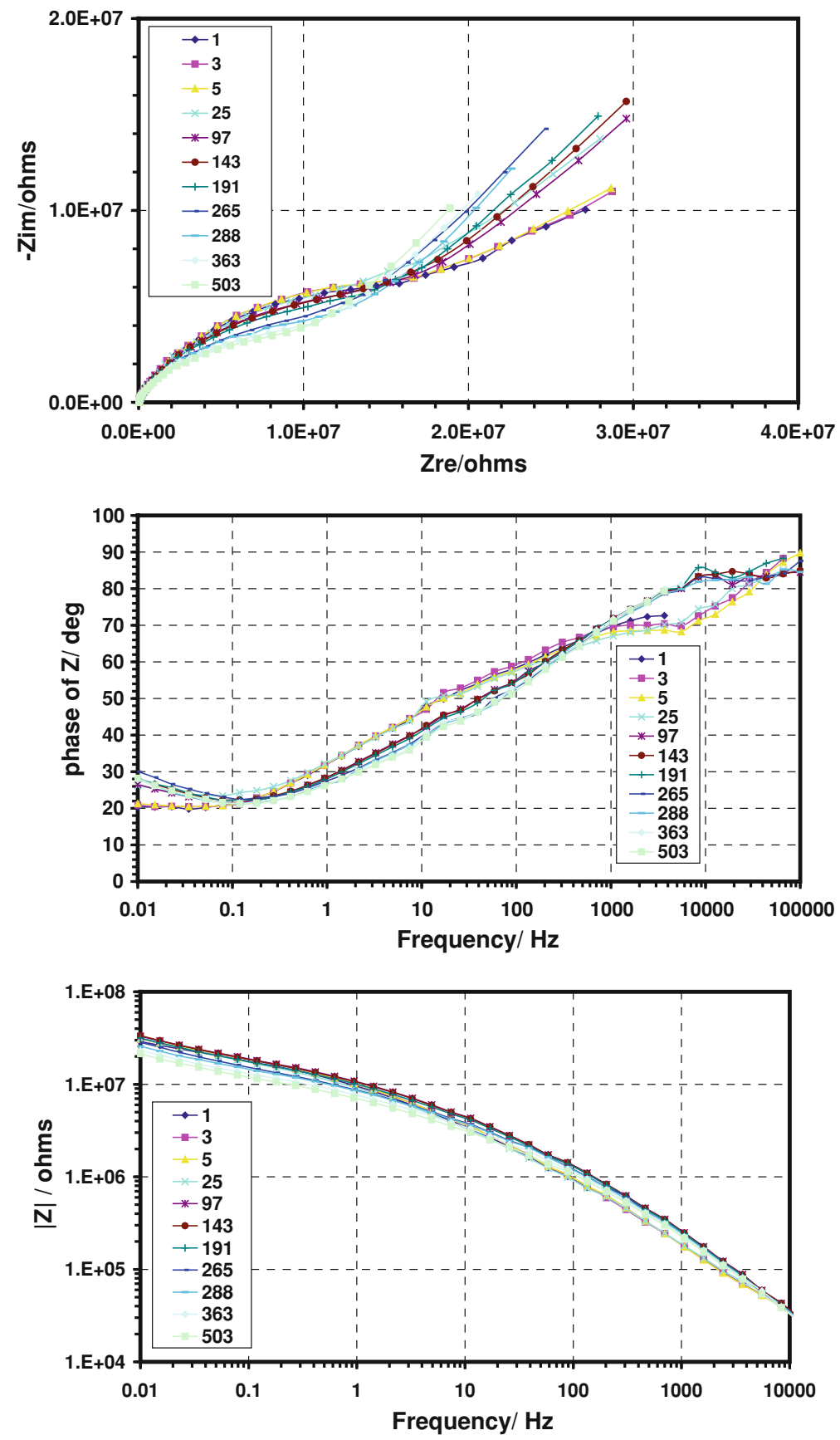

Fig. 4 EIS curves obtained from Ti-47Al-2Cr sample thermally treated at $950{ }^{\circ} \mathrm{C}$ then placed in Ringer's solution for different exposure times 
Table 2 Fitted results from EIS curves obtained from Ti-47Al-2Cr sample thermally treated at $950{ }^{\circ} \mathrm{C}$ then placed in Ringer's solution for different exposure times

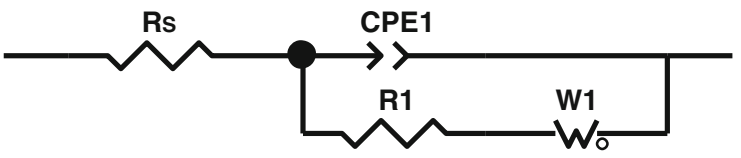

\begin{tabular}{lcllll}
\hline Exposure time $(\mathrm{h})$ & $\mathrm{Rs}\left(\Omega \mathrm{cm}^{2}\right)$ & $\mathrm{R} 1\left(\mathrm{M} \Omega \mathrm{cm}^{2}\right)$ & $\mathrm{CPE}_{1}-\mathrm{T}\left(\mathrm{nF} \mathrm{cm} \mathrm{cm}^{-2}\right)$ & $\mathrm{CPE}_{1}-\mathrm{P}$ & $\sigma\left(\mathrm{M}^{2} \mathrm{~cm}^{2} \mathrm{~S}^{1 / 2}\right)$ \\
\hline 1 & $1,805^{\mathrm{a}}$ & 23 & 75 & 0.53 & 0.91 \\
3 & $201^{\mathrm{a}}$ & 23 & 70 & 0.55 & 1.00 \\
5 & 20 & 23 & 70 & 0.55 & 1.05 \\
25 & 268 & 22 & 80 & 0.54 & 1.40 \\
97 & 392 & 24 & 60 & 0.50 & 1.50 \\
143 & 351 & 24 & 70 & 0.50 & 1.70 \\
191 & $92^{\mathrm{a}}$ & 21 & 70 & 0.50 & 1.60 \\
265 & 165 & 16 & 75 & 0.50 & 1.55 \\
288 & 375 & 16 & 70 & 0.53 & 1.25 \\
363 & $160^{\mathrm{a}}$ & 13 & 70 & 0.55 & 1.10 \\
503 & $205^{\mathrm{a}}$ & 11 & 70 & 0.58 & 1.00 \\
\hline
\end{tabular}

${ }^{a}$ Denotes more than $10 \%$ error in fitting the equivalent circuits

$$
Z_{\mathrm{w}}=\frac{\sigma}{\sqrt{\omega}}-\frac{\sigma}{\sqrt{\omega}} j
$$

where, $\omega$ is the angular frequency and $\sigma$ the Warburg coefficient, which can be used for calculation of the diffusion coefficient. This equation states that at each frequency the real and imaginary parts of the Warburg impedance are equal, and are proportional to $\frac{1}{\sqrt{\omega}}$. In the Nyquist curve the Warburg impedance is shown by a straight line with a slope of -1 [20].

It is apparent from Table 2 that values did not change with increasing exposure to Ringer's solution. Although changes in resistance, capacitance, and Warburg impedance occurred, it seems that the layer gradually became more resistant and then lost some of its resistance and reach to the initial values after $500 \mathrm{~h}$. Errors were greatest for the solution resistances indicated.

Figure 5 shows the impedance curves for a sample tested in more aggressive solution, i.e. $3.5 \% \mathrm{NaCl}$ solution. It is apparent that, initially, the total resistance (the impedance modulus at low frequency) was almost a factor of 100 less than that for Ringer's solution, but as time increased $(35 \mathrm{~h})$ the resistance increased substantially and reached values approximately one tenth of values for Ringer's solution. A similar equivalent circuit was used to fit the results. For the first and third hours different circuits were used for fitting; this was similar to use of a circuit with two RC loops that is used for coatings with defects.

Table 3 shows the equivalent circuit and fitted results for the impedance curves. By comparing these results with those obtained from use of Ringer's solution, it can 

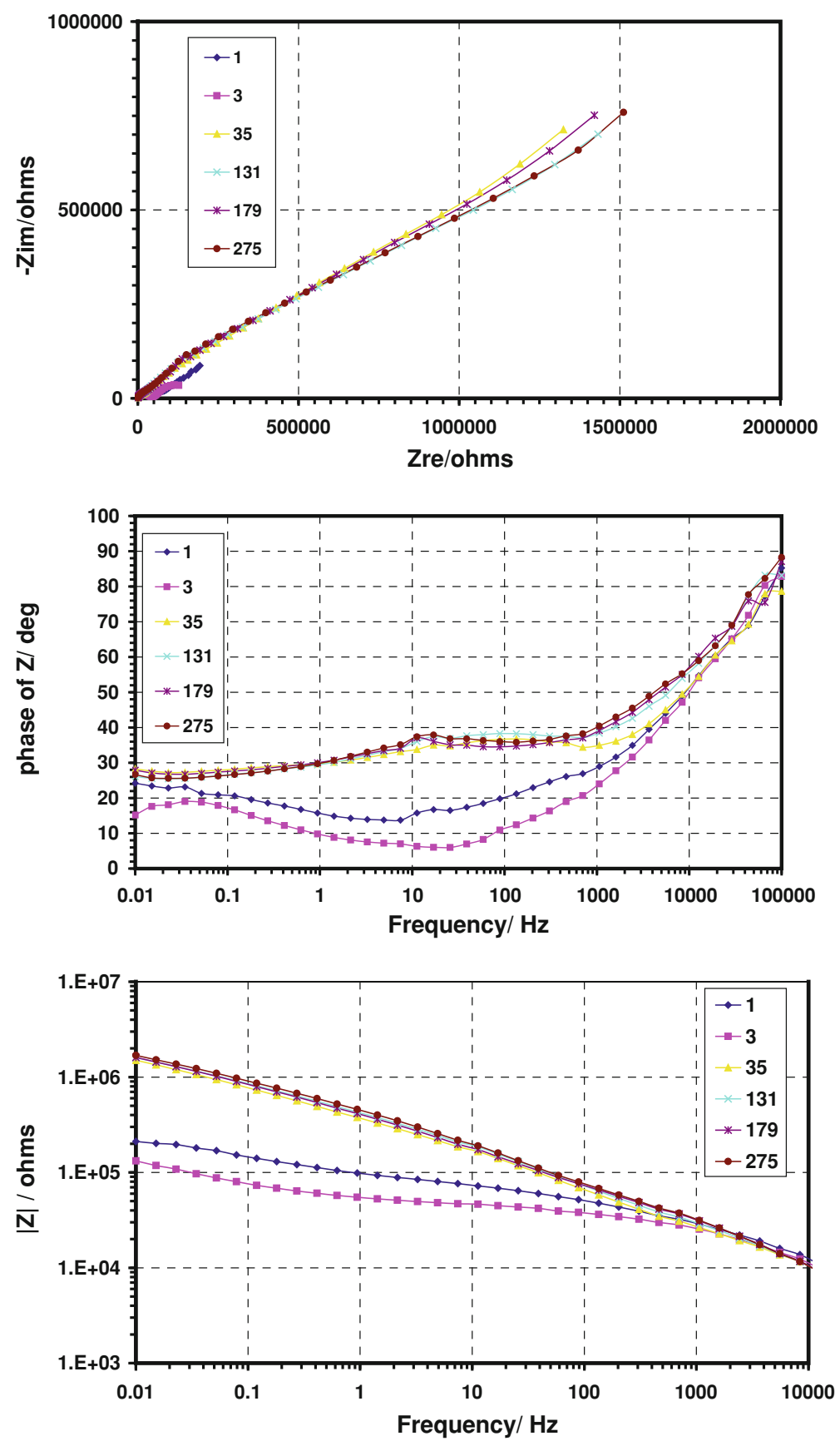

Fig. 5 EIS curves obtained from Ti-47Al-2Cr sample thermally treated at $950{ }^{\circ} \mathrm{C}$ then placed in $3.5 \%$ $\mathrm{NaCl}$ solution for different exposure times 
Table 3 Fitted results from EIS curves obtained from Ti-47Al-2Cr sample thermally treated at $950{ }^{\circ} \mathrm{C}$ then placed in $3.5 \% \mathrm{NaCl}$ solution for different exposure times
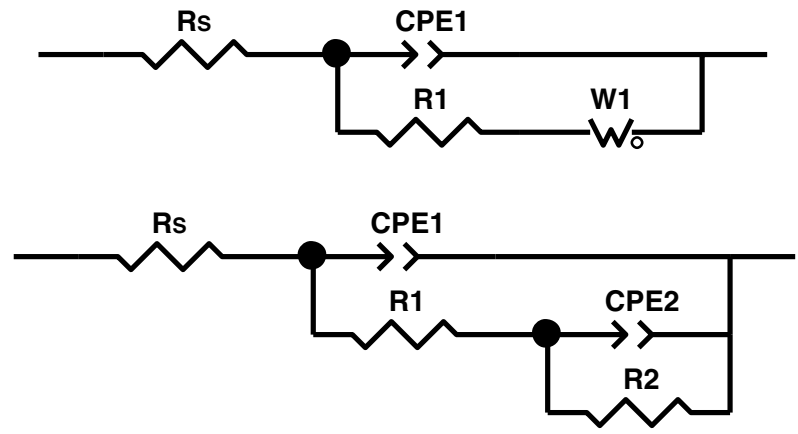

\begin{tabular}{lllllllll}
\hline $\begin{array}{l}\text { Exposure } \\
\text { time }(\mathrm{h})\end{array}$ & $\begin{array}{l}\mathrm{R}_{\mathrm{s}} \\
\left(\Omega \mathrm{cm}^{2}\right)\end{array}$ & $\begin{array}{l}\mathrm{R}_{1} \\
\left(\mathrm{k} \Omega \mathrm{cm}^{2}\right)\end{array}$ & $\begin{array}{l}\mathrm{CPE}_{1}-\mathrm{T} \\
\left.(\mu \mathrm{F} \mathrm{cm})^{-2}\right)\end{array}$ & \begin{tabular}{l}
$\mathrm{CPE}_{1}-\mathrm{P}$ \\
\hline 1
\end{tabular} & $\begin{array}{l}\sigma \\
\left(\mathrm{k} \Omega \mathrm{cm}^{2}\right. \\
\left.\mathrm{S}^{1 / 2}\right)\end{array}$ & $\begin{array}{l}\mathrm{R}_{2} \\
\left(\mathrm{M} \Omega ~ c m^{2}\right)\end{array}$ & $\begin{array}{l}\mathrm{CPE}_{2}-\mathrm{T} \\
\left.(\mu \mathrm{F} \mathrm{cm})^{-2}\right)\end{array}$ & $\mathrm{CPE}_{2}-\mathrm{P}$ \\
1 & $45^{\mathrm{a}}$ & 7.9 & 3.0 & 0.50 & 10 & - & - & - \\
3 & $40^{\mathrm{a}}$ & 8 & 2.9 & 0.53 & - & 1.50 & 70 & 0.50 \\
35 & $10^{\mathrm{a}}$ & 4.6 & 0.7 & 0.55 & - & 0.15 & 80 & 0.58 \\
131 & $280^{\mathrm{a}}$ & 1,000 & 2.0 & 0.50 & 92 & - & - & - \\
179 & $212^{\mathrm{a}}$ & 1,200 & 1.8 & 0.50 & 80 & - & - & - \\
275 & 50 & 1,300 & 2.0 & 0.50 & 85 & - & - & - \\
\hline
\end{tabular}

${ }^{a}$ Denotes more than $10 \%$ error in fitting the equivalent circuits

be seen that the biggest difference is for the Warburg element, which is almost a factor of 100 less, which is indicative of easier charge carrier diffusion through the surface film in the presence of higher concentrations of chloride ion in solution. Nevertheless, the values are still high in comparison with those for other coatings.

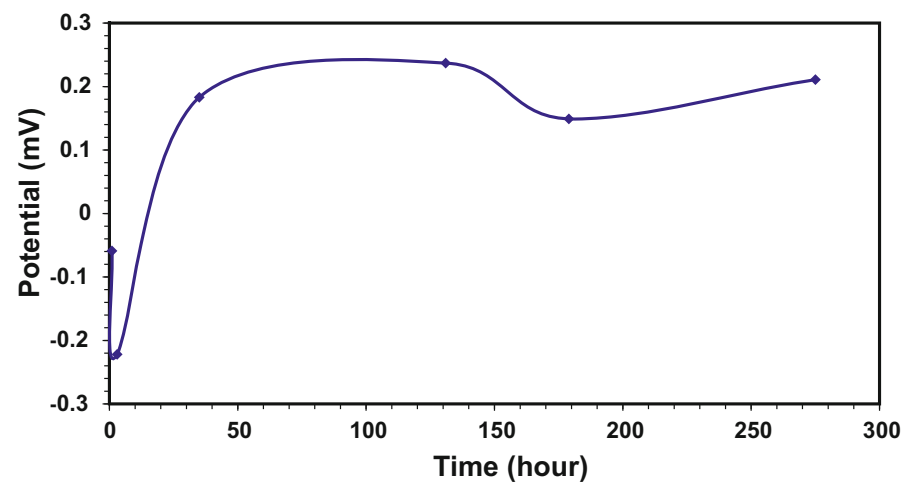

Fig. 6 Variation of the free potential of Ti-47Al-2Cr sample thermally treated at $950{ }^{\circ} \mathrm{C}$ then placed in $3.5 \% \mathrm{NaCl}$ solution for different exposure times 

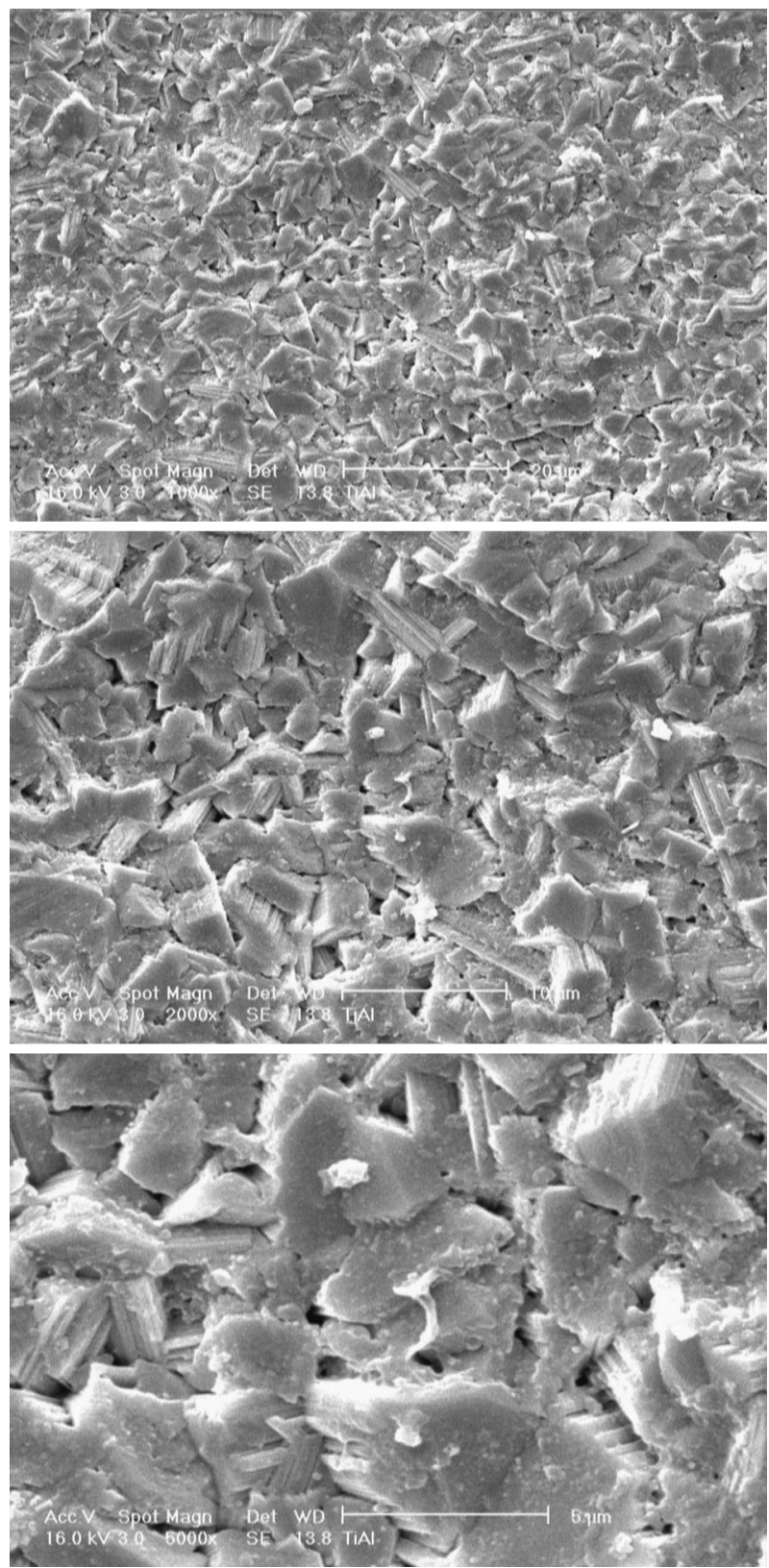

Fig. 7 Scanning electron micrographs, with different magnification, of the upper surface of the oxide film formed by thermal treatment of Ti-47Al-2Cr sample at $950{ }^{\circ} \mathrm{C}$

Figure 6 shows free potential changes of the sample at different times. Measurement was performed immediately before performing impedance tests. Exactly similar to the impedance changes, the sample potentials in the first and third 


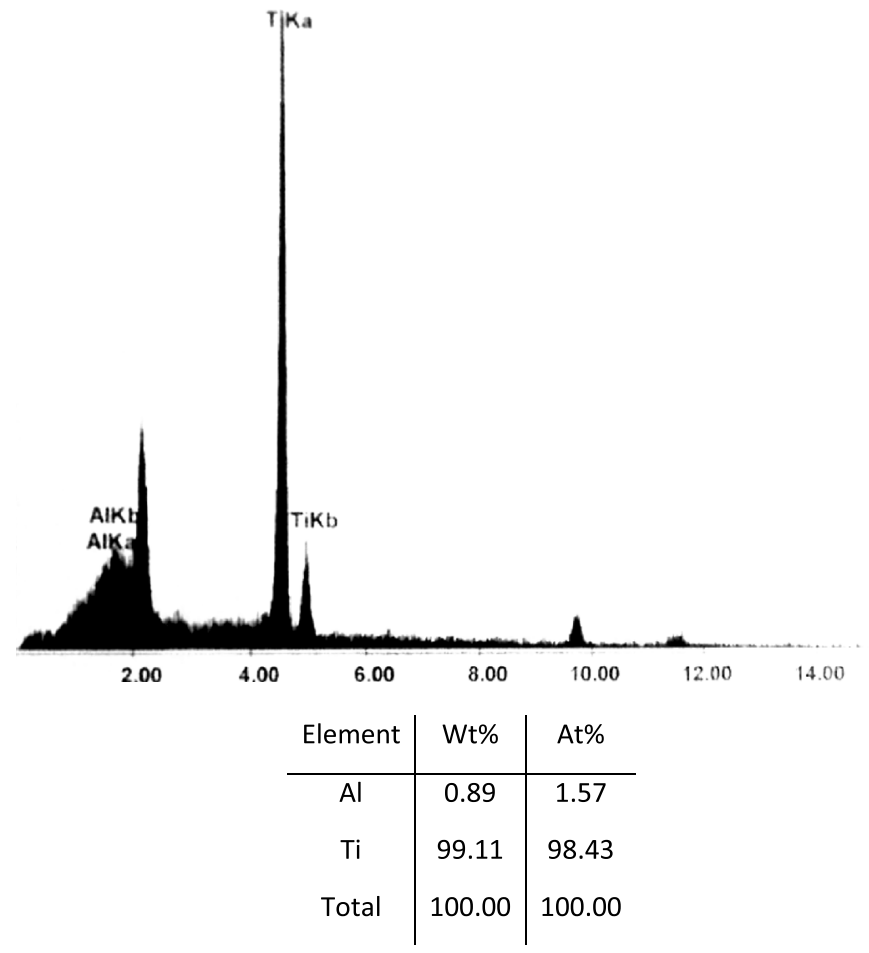

Fig. 8 EDS analysis of the upper surface of the oxide film formed by thermal treatment of Ti-47Al-2Cr sample at $950{ }^{\circ} \mathrm{C}$

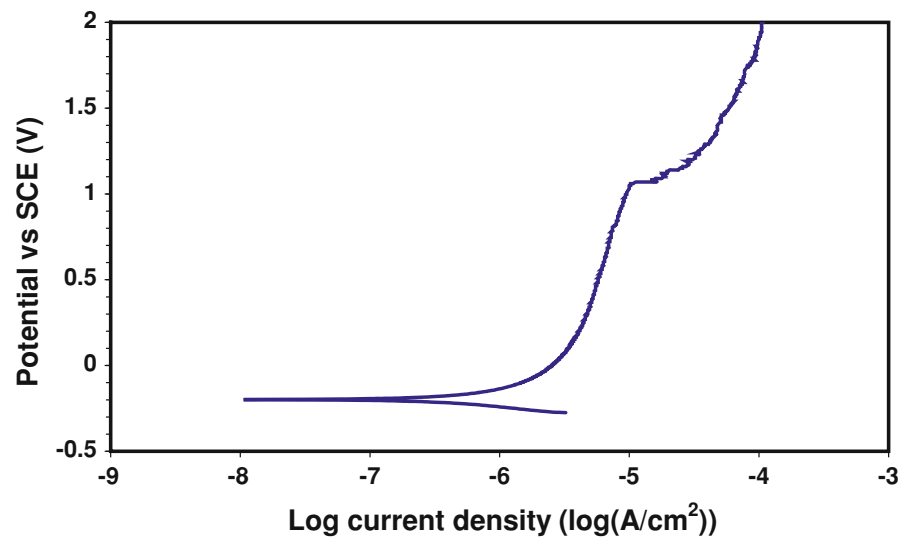

Fig. 9 Potentiodynamic polarization curve of $\mathrm{Ti}-47 \mathrm{Al}-2 \mathrm{Cr}$ sample thermally treated at $950{ }^{\circ} \mathrm{C}$ then placed in $3.5 \% \mathrm{NaCl}$ solution for $275 \mathrm{~h}$

hours decreased, then rose substantially again and remained constant. This can be explained by studying the scanning electron micrographs of the sample surface. As observed in Fig. 7 at different magnifications, the oxide surface of the outer layer is 
Table 4 Results extracted from potentiodynamic polarization curve of Ti-47Al-2Cr sample thermally treated at $950{ }^{\circ} \mathrm{C}$ then placed in $3.5 \% \mathrm{NaCl}$ solution for $275 \mathrm{~h}$

\begin{tabular}{llllll}
\hline $\begin{array}{l}\text { Corrosion rate } \\
(\mathrm{mpy})\end{array}$ & $\begin{array}{l}E(\mathrm{I}=0) \\
(\mathrm{mV})\end{array}$ & $\begin{array}{l}\text { Icorr } \\
(\mathrm{nA})\end{array}$ & $\begin{array}{l}\text { Beta anodic } \\
(\text { V/decade })\end{array}$ & $\begin{array}{l}\text { Beta cathodic } \\
(\text { V/decade })\end{array}$ & $\begin{array}{l}\text { Epit } \\
(\mathrm{mV})\end{array}$ \\
\hline 0.711 & -198 & 244 & 0.617 & 0.182 & 1,070 \\
\hline
\end{tabular}
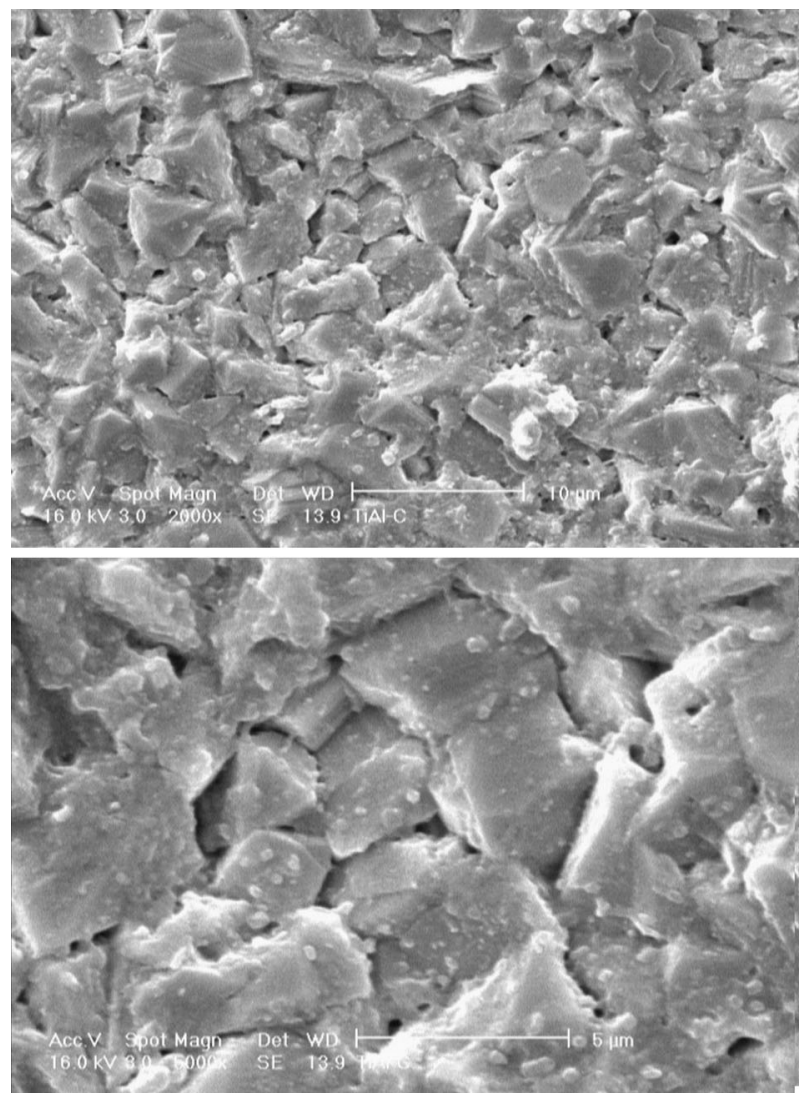

Fig. 10 Scanning electron micrographs of the upper surface of the oxide film formed by thermal treatment of Ti-47Al-2Cr sample at $950{ }^{\circ} \mathrm{C}$ after potentiodynamic polarization test in $3.5 \% \mathrm{NaCl}$ solution

scaly in form, with overlapping scales. Evidently there is a barrier layer underneath, which can be identified from the cross section (Fig. 2). The outer layer is composed of titanium oxides with a compositional analysis given in Fig. 8. Initially, aggressive ions diffuse from the surface holes to the inner parts and cause charge transfer and corrosion, but over time, the titanium and aluminium oxides hydrolyze in the inner parts and form voluminous hydroxides and the holes blocked from the interior so the impedance of the system increases; because of the more difficult 
diffusion the Warburg values increase. Because of the presence of the barrier layer and surface blockages, the surface potential changes to a more positive value.

After exposure to $3.5 \% \mathrm{NaCl}$ solution for $275 \mathrm{~h}$ the sample was examined by potentiodynamic polarization. The resulting curve is illustrated in Fig. 9. The rate of corrosion and breakdown of potential are presented in Table 4. Figure 10 shows the surface of the sample after $2,000 \mathrm{mV}$ anodic polarization; it is little different from that of the sample without exposure or polarization (Fig. 7). It can be concluded that the Ti-47Al-2Cr sample coated by this method has outstanding resistance against corrosion in chloride solutions and for extended periods of time.

In an study conducted by Alvarado et al. $[4,11]$, a passive oxide film formed on Ti-48Al-2Cr-2 $\mathrm{Nb}$ by oxidation in air at 500 and $800{ }^{\circ} \mathrm{C}$ enhanced the corrosion resistance by a factor of 100 . The high corrosion resistance of the oxide film observed in this study can be attributed to the composition and morphology of the layer formed. The outstanding and rather unusual corrosion resistance of modified TiAl intermetallic alloy in Ringer's solution can be justified qualitatively by considering the composition and microstructures of the oxide phases formed. Because of the low conductivity of $\mathrm{Al}_{2} \mathrm{O}_{3}$ and $\mathrm{TiO}_{2}$, electron transfer through the surface layer is difficult and the resistance to electrical charge transfer is increased; both prevent electrochemical corrosion [21]. Furthermore, the compact interface and excellent contact of the surface oxide layer with the metal substrate is another important factor for improvement of corrosion behavior.

\section{Conclusion}

Thermal passivation of $\mathrm{Ti}-47-2 \mathrm{Cr}$ (at. \%) samples in the presence of nitrogen gas flow has been tested by immersion of the samples in Ringer's solution and in $3.5 \%$ $\mathrm{NaCl}$ solution for different times and study by electrochemical impedance spectroscopy. The proposed equivalent circuit for fitting the impedance curves included a Warburg element, which was indicative of diffusion control of charge transfer through the passive surface layer. The results showed that layer resistance did not decrease substantially after exposure for up to $300 \mathrm{~h}$ and, on the basis of SEM images, the surface was not damaged.

\section{References}

1. E.A. Loria, Intermetallics 8, 1339 (2000)

2. E.A. Loria, Intermetallics 9, 997 (2001)

3. C.M. Austin, Curr. Opin. Solid State Mater. Sci. 4, 239 (1999)

4. D.C. Alvarado, P.A. Sundaram, Acta Biomater. 2, 701 (2006)

5. D.C. Alvarado, P.A. Sundaram, Corros. Sci. 49, 3732 (2007)

6. O.R. Denizard, N.C. Diffoot, V. Navas, P. Sundaram, J. Mater. Sci. Mater. Med. 19, 153 (2008)

7. E. Saebnoori, T. Shahrabi, A. Sabour, M. Jafarian, Anti-Corros. Method. M. 59, 51 (2012)

8. M.C. García-Alonso, L. Saldaña, G. Vallés, J.L. González-Carrasco, J. González-Cabrero, M.E. Martínez, E. Gil-Garay, L. Munuera, Biomaterials 24, 19 (2003)

9. J.W. Fergus, Mater. Sci. Eng., A 338, 108 (2002) 
10. M.F. Lopez, A. Gutierrez, J. Jiménez, Electrochim. Acta 47, 1359 (2002)

11. D.C. Alvarado, A study of the corrosion resistance of gamma titanium aluminide in Ringer's solution, 3.5wt\% $\mathrm{NaCl}$ and seawater, Mechanical Engineering, University of Puerto Rico, 2005

12. O.R. Denizard, Biocompatibility Studies of Human FetalOsteoblast Cell on Titanium Aluminide, Biology (University of Puerto Rico, Puerto Rico, 2005)

13. H. Güleryüz, H. Çimenoglu, Biomaterials 25, 3325 (2004)

14. W. Lu, C.L. Chen, L.L. He, F.H. Wang, J.P. Lin, G.L. Chen, Corros. Sci. 50, 978 (2008)

15. Y. Umakoshi, M. Yamaguchi, T. Sakagami, T. Yamane, J. Mater. Sci. 24, 1599 (1989)

16. S. Kekare, P. Aswath, J. Mater. Sci. 32, 2485 (1997)

17. Y. Song, X. Zhu, X. Wang, J. Che, Y. Du, J. Appl. Electrochem. 31, 1273 (2001)

18. B. Zhao, J. Wu, J. Sun, B. Tu, F. Wang, Intermetallics 9, 697 (2001)

19. A.R. Rastkar, B. Shokri, T. Bell, Surf. Coat. Technol. 202, 6038 (2008)

20. D.D. Macdonald, Electrochim. Acta 51, 1376-1388 (2006)

21. I. Milošev, M. Metikoš-Huković, H.H. Strehblow, Biomaterials 21, 2103 (2000) 